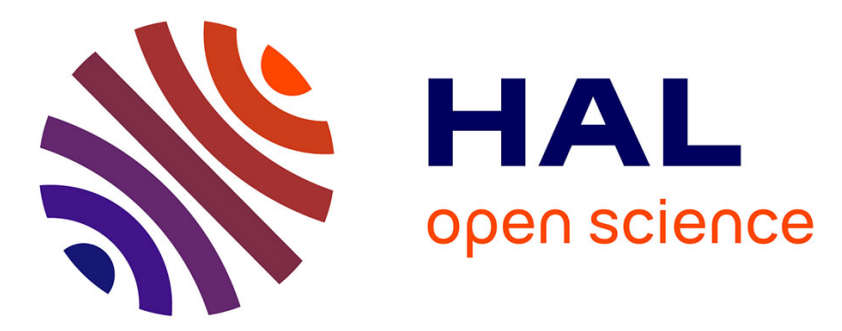

\title{
Analysis of charging kinetics on space dielectrics under representative worst case geostationary conditions
}

\author{
T. Paulmier, A. Sicard-Piet, D. Lazaro, D. Payan, N. Balcon
}

\section{To cite this version:}

T. Paulmier, A. Sicard-Piet, D. Lazaro, D. Payan, N. Balcon. Analysis of charging kinetics on space dielectrics under representative worst case geostationary conditions. Spacecraft Charging Technology Conference 2014 (13th SCTC), Jun 2014, PASADENA, United States. hal-01081930

\section{HAL Id: hal-01081930 \\ https://hal.science/hal-01081930}

Submitted on 12 Nov 2014

HAL is a multi-disciplinary open access archive for the deposit and dissemination of scientific research documents, whether they are published or not. The documents may come from teaching and research institutions in France or abroad, or from public or private research centers.
L'archive ouverte pluridisciplinaire HAL, est destinée au dépôt et à la diffusion de documents scientifiques de niveau recherche, publiés ou non, émanant des établissements d'enseignement et de recherche français ou étrangers, des laboratoires publics ou privés. 
$(151)$

\title{
Analysis of charging kinetics on space dielectrics under representative worst case geostationary conditions
}

\author{
T. Paulmier, A. Sicard-Piet, D. Lazaro, D. Payan, N. Balcon
}

\begin{abstract}
Prediction of charging behaviour of space used materials often raise the issue on the definition of the applied electron energy spectrum used for irradiation under representative conditions. Radiation induced conductivity (RIC) can not be discarded for a proper qualification of these materials. But RIC level is significantly dependent upon radiation dose and dose rate. We have been able to demonstrate that the applied energy spectra lead to strong and hazardous charging levels, when radiation history is not regarded. However, charging effect is strongly smoothed by radiation history of the material. We have been able therefore to reveal in this study that a good electric qualification of space materials under electron irradiation requires the definition of realistic electron energy spectrum and implies to take into account radiation history in space.
\end{abstract}

Keywords-Charging kinetics, space environment, worst case conditions, radiation history, radiation induced conductivity

\section{INTRODUCTION}

Experimental characterization of charging behaviour of space used materials often raise the issue on the definition of the applied electron energy spectrum used for irradiation under representative conditions. The application of a simple low energy $(20 \mathrm{keV})$ electron beam for this characterization would lead to high charging kinetics for most dielectrics materials, which is not representative of what we can observe in space. Indeed, this kind of electron beam only induces surface charging and bulk properties are not affected. In reality, space materials have to cope with high energy electron radiation (up to several Megaelectronvolts) that ionizes the overall material bulk and especially enhances their electric conductivity, impinging then on their charging kinetics. We speak then about radiation induced conductivity (RIC) which is triggered by high energy electrons. Fig. 1 compares charging kinetics measured on polyimide Kapton ${ }^{\circledR}$ irradiated either by monoenergetic $20 \mathrm{keV}$ electron beam or by a representative distributed electron energy spectrum $(\mathrm{Kp}>5)$. We can then notice that RIC is initiated in the material bulk for representative conditions, leading to much lower absolute surface potential than expected with low energy irradiation.

T. Paulmier, A. Sicard-Piet and D. Lazaro are with ONERA, The French Aerospace Lab, Toulouse F-31055, France (e-mail:

Thierry.Paulmier@onera.fr)

D. Payan and N. Balcon are with CNES, The French Space Agency, 31401Toulouse Cedex 9, France

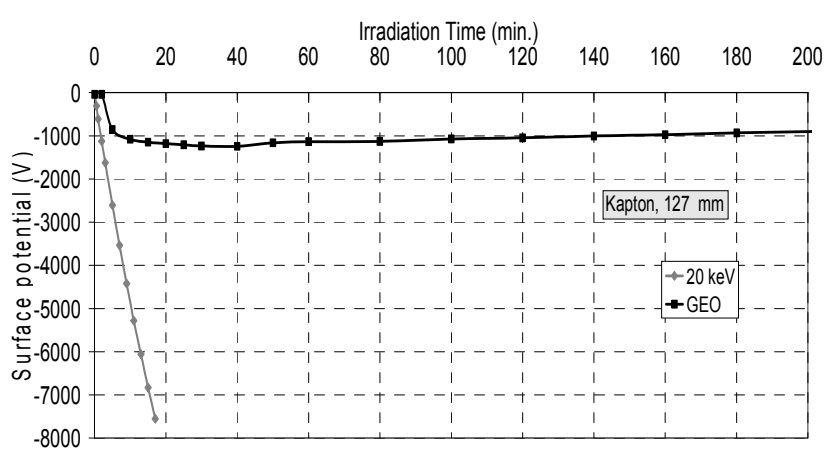

Fig. 1. Evolution of surface potential measured on $127 \mu \mathrm{m}$ thick Kapton ${ }^{\circledR}$ under monoenergetic $20 \mathrm{keV}$ electron irradiation or high energy geostationary (GEO) like electron irradiation

It is therefore of high importance to take into account effect of this high energy irradiation for good and realistic qualification of spacecraft materials. This approach has been applied at ONERA and CNES in which the SIRENE experimental facility has been developed to reproduce different electron energy spectra met in space in the $[0-400] \mathrm{keV}$ energy range and to perform thorough electric analysis on the materials for their qualification and the extraction of electric properties [1,2]. The devised electron energy reference spectrum in SIRENE is representative of geostationary irradiation conditions in which fluxes of high energy electrons are quite high, leading to significant leakage current (due to radiation induced conductivity [RIC]). Fig. 2 presents the integrated electron spectrum produced with the SIRENE facility in comparison with the Kp $>5$ geostationnary spectrum. 
(151)

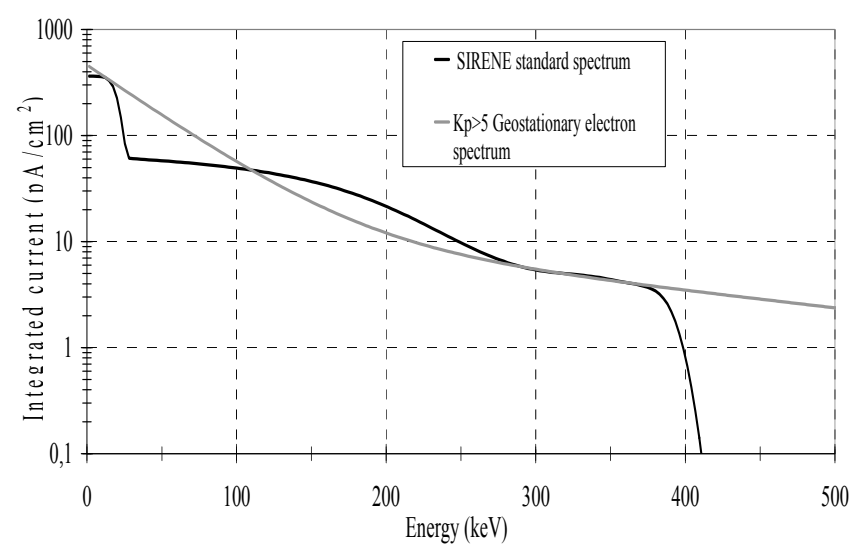

Fig. 2. SIRENE standard spectrum and reference $\mathrm{KP}>5$ spectrum

In some conditions however (pre-storm conditions), satellites may have to cope with different conditions in which charging low energy fluxes are very high in comparison with the high energy ionizing fluxes. In other words, the ratio between low energy and high energy fluxes could be much higher in these conditions than in $\mathrm{Kp}>5$ or in average irradiation cases : charging kinetics should then be higher due to lower RIC and higher charging flux.

A comprehensive study has been carried out at ONERA to study the occurrence of geostationary worst case conditions for which the flux ratio between low and high energy electrons is the highest (but still representative). The above irradiation condition shall be a worst case condition for charging since RIC should be fairly low. This study has been performed through numerical analysis from space databases. Data from geostationary spacecraft from LANL (Los Alamos National Laboratory) between 1990 and 2008 have been studied and worst case spectra have been extracted for different temporal integration times.

Radiation history preceding these worst conditions has also been extracted to take into account the delayed ionizing effect. Radiation conductivity induced by high energy radiation does indeed prevail for a long period of time, which then affects the charging properties of materials over time in worst case conditions. This delayed conductivity due to radiation history can then strongly smooth the worst case conditions effect by enhancing the overall material conductivity. Delayed effect is conspicuous in Fig. 3 in which charging kinetics is presented for Kapton ${ }^{\circledR}$ submitted to successive representative irradiations: we can then notice that Kapton ${ }^{\circledR}$ is more conductive during the second set due to the delayed radiation conductivity induced by the first high energy irradiation.

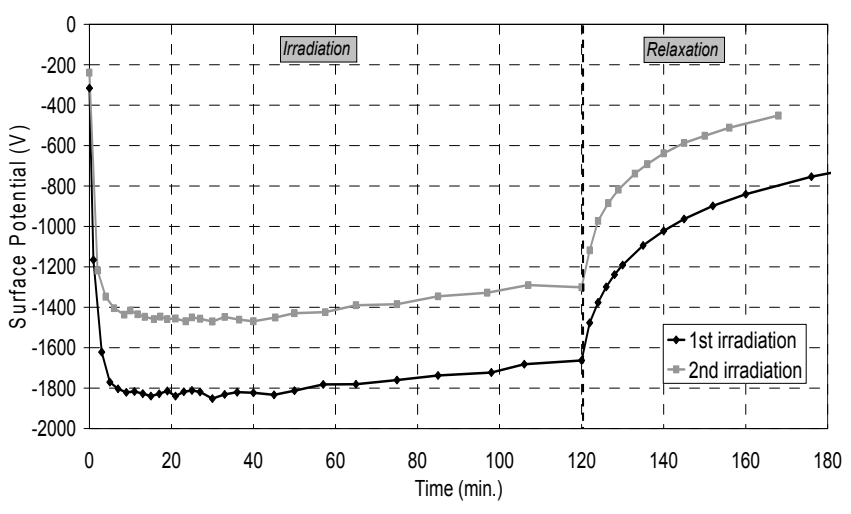

Fig. 3. Evolution of surface potential measured on $127 \mu$ m thick Kapton during two successive GEO electron irradiations $(15 \mathrm{~h}$ relaxation between both irradiations)

Following the definition of worst case spectra and the involved radiation history, numerical analyses have then been performed to study the charging behaviour of space dielectric materials under these representative electron energy spectra (with or without radiation history). A numerical model developed at ONERA for the simulation of charge transport and RIC effect in dielectrics has been used for this study and is presented in this paper. This model allows the assessment of charge kinetics under multi-energetic electron irradiation. Evolution of RIC with radiation dose rate and total radiation dose, as well as delayed ionizing effect (due to long term irradiation), are calculated in this model. The numerical study has been carried out on polyimide Kapton ${ }^{\circledR}$ and allowed demonstrating the effect of worst case conditions and radiation history in charging kinetics. These numerical results are presented in a second part of this paper.

\section{DEFINITION OF WORST CASE SPECTRA AND THEIR RADIATION HISTORY}

\section{A. Worst case spectra}

The objective of this study was to extract from flight data conditions in which ratio between low energy $(<40 \mathrm{keV})$ flux and high energy flux $(>40 \mathrm{keV})$ is the highest, for a given integrated irradiation duration ( 5 minutes, 15 minutes, 1 hour, 6 hours, 1 day, 7 days) and a given sampling period (1 month, 1 year, 5 years). The overall analysis has been performed over 15 years collected data which allows getting information of the occurrence probability of these worst case conditions. Taking a 5 years period, we would then get 3 worst case spectra over the 15 years collected data (for a given irradiation duration); for 1 year, we would get 15 spectra and for 1 month period, 180 spectra.

Fig. 4 presents the electron spectrum for 15 minutes irradiation duration and 1 month sampling period, averaged over the 180 collected spectra. The integrated spectrum is compared with the referenced SIRENE spectrum applied for the material characterization (Fig. 5). From this figure, we can then notice that the low / high energy flux ratio is much higher for the extracted spectra that the one observed on the $\mathrm{Kp}>5$ 
(151)

spectrum: this would then lead, as we will see later, to a higher charging kinetics due especially to a lower RIC.

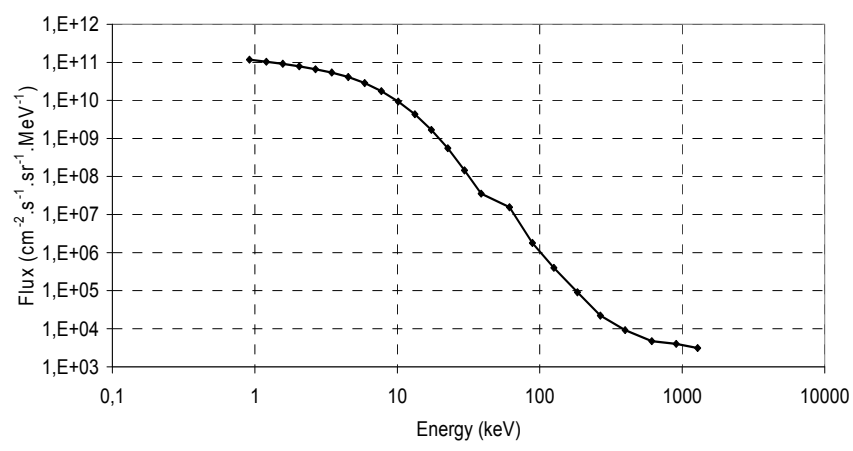

Fig. 4. Electron energy spectrum for worst case scenario with $15 \mathrm{~min}$. integration duration and 1 month sampling period

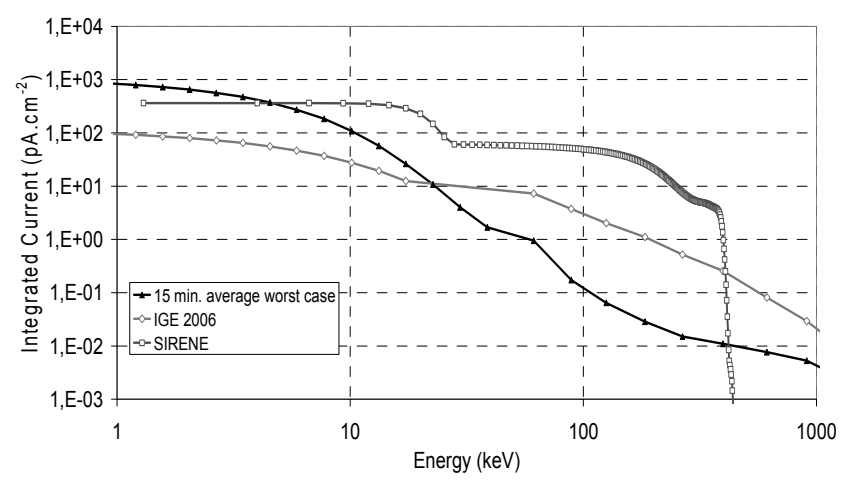

Fig. 5. Integrated electron current for the $15 \mathrm{~min}$. worst case spectrum, the reference SIRENE spectrum and the IGE 2006 [3] spectrum (in the integrated spectrum, the value read at a given energy level corresponds the sum of fluxes for energies higher than this level)

If the integrated duration increases, this lead to a decrease of the low / energy ratio since rapid injection effects are smoothed by time averaging, as we can see in Fig. 6 for an integration irradiation time equal to 7 days and a sampling period of 1 month. This averaging leads especially to a significant decrease of the low energy charging part.

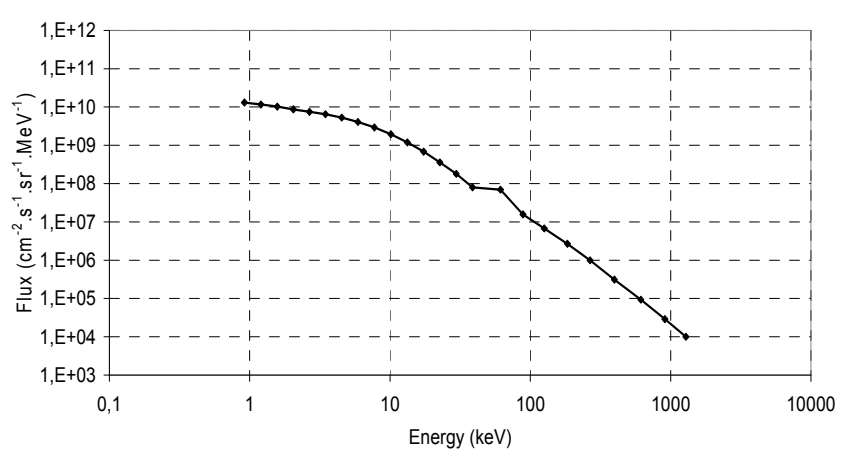

Fig. 6. Electron energy spectrum for worst case scenario with 7 days intregration duration and 1 month sampling period

\section{B. Radiation history of the worst case spectra}

As mentioned in the introduction part, it is of high importance, for a proper material qualification to take into account the radiation dose received by the material before the occurrence of the worst case spectrum. Through delayed effects, RIC can be significantly enhanced by radiation history leading to a lower charging kinetics. A spectrum preceding worst case conditions (for integration irradiation time equal to 5 minutes, 15 minutes or 1 hour) has been assessed at different integrated duration (1 day, 1 week, 1 month, 1 year) as we can see in Fig. 7. We can notice that there is no evolution of this spectrum with the integrated duration and that these "historic" spectra are close to the reference IGE spectrum [3] (Fig. 8), independently of the integration durations.

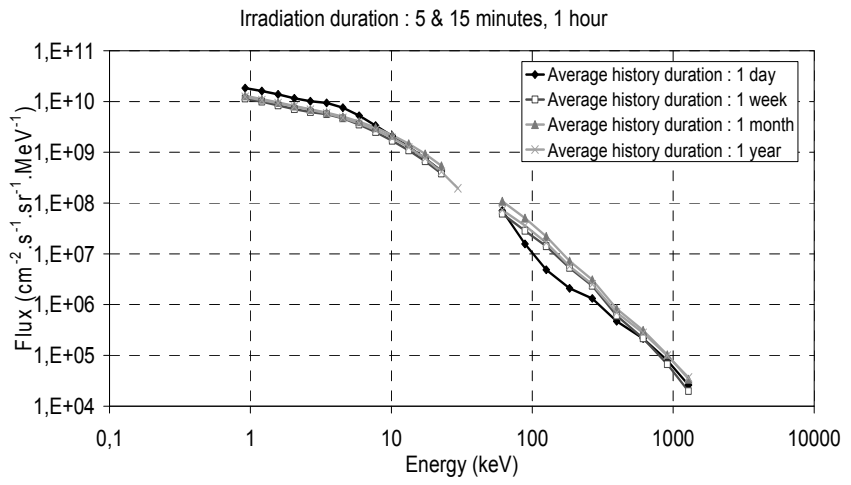

Fig. 7. Electron averaged spectrum preceding worst case charging conditions (for worst case irradiation duration equal to $5 \mathrm{~min} ., 15 \mathrm{~min}$. and 1 hour) 


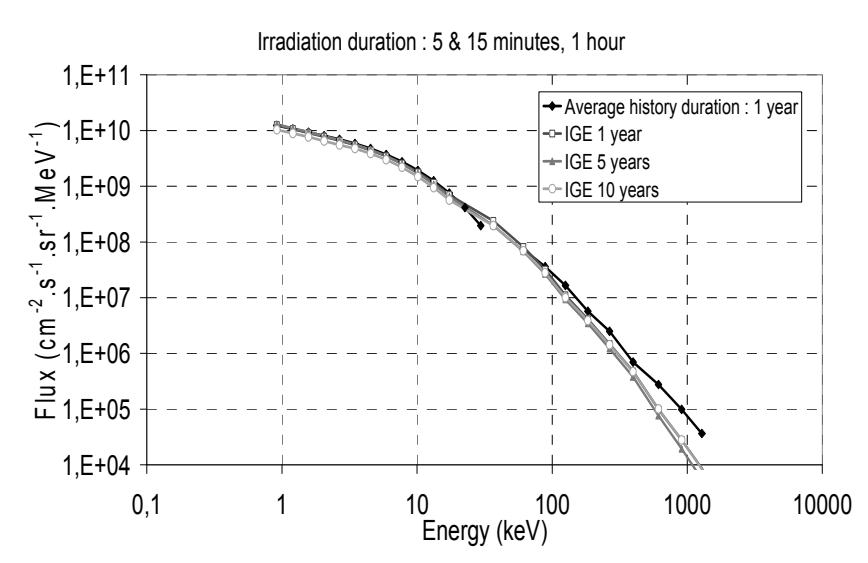

Fig. 8. Comparison between the assessed "history" spectrum (averaged over 1 year) and the referenced IGE spectra (assessed for 1 year, 5 and 10 years)

This averaged radiation history is also not dependent on the time of occurrence of the worst case scenario, as we can see in Fig. 9 in which the "historic" spectrum (averaged over 1 year) has been assessed along the overall solar cycle (11 years) prior the worst case scenario met each year.

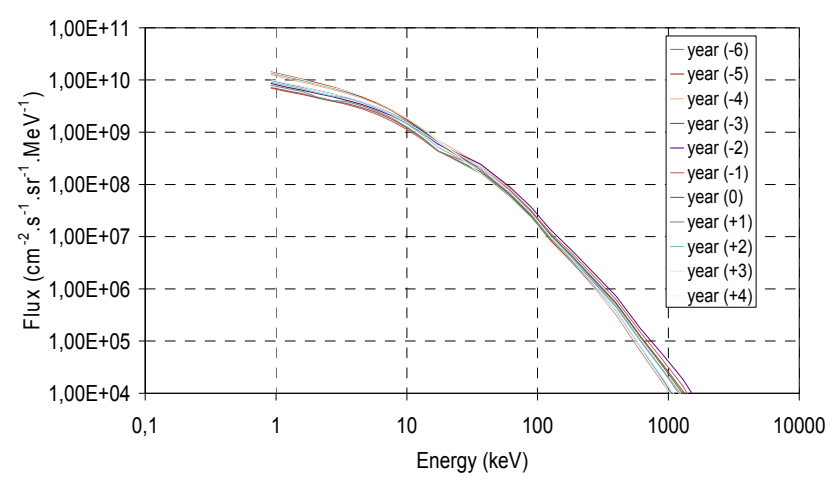

Fig. 9. Evolution of the "history" averaged spectrum preceding 1 hour worst case conditions as a function of the "worst case" occurence time

\section{PHYSICS MODEL FOR ANALYSIS OF CHARGING KINETICS}

The second part of this work was to study the effect of the socalled worst case spectra on the charging kinetics of space used polymers. A numerical assessment of charging potential built-up at the surface of a $127 \mu \mathrm{m}$ thick Kapton ${ }^{\circledR}$ piece has been performed for different irradiation conditions. For this task, a basic 0D model, initially developed by Rose [4], Fowler [5] and Gross [6] and then amended in our laboratory has been used for the assessment of charging kinetics and RIC effect in given irradiation conditions. RIC is steered by different physical mechanisms: generation of electron-hole pairs by high energy electrons, trapping, detrapping and recombination of both charge carriers, mobility of charge carrier under the applied electric field. The amended OD model allows taking into account these different effects. In this model, the rate of free electrons and holes, generated by the high electron beam, and named $g$ factor, is constant and uniform over time. Two levels of localized traps have been implemented in this model for both charge carriers: one deep trap for which detrapping should be very low but should act as recombination centres if filled with electrons; a second trap corresponding to middle energy depth and for which detrapping is easier. Shallower traps are supposed to be in thermal equilibrium with the extended state. Mobility for free charges is therefore an average mobility taking into account this thermal equilibrium process. We assume as well that a free charge recombines with a localized charge with opposite sign, as assumed by Gross [6]. Based on the above assumptions and introducing charge detrapping process in the model, the equations describing the 0D RIC model are:

$$
\begin{aligned}
\mathrm{dn} / \mathrm{dt}=\mathrm{g}-\alpha_{1} \cdot \mathrm{n} \cdot\left(\mathrm{p}_{\mathrm{t} 1}+\mathrm{p}_{\mathrm{t} 2}\right)-\mathrm{n} / \tau_{\mathrm{n} 1}-\mathrm{n} / \tau_{\mathrm{n} 2}+\mathrm{n}_{\mathrm{t}} / \tau_{\mathrm{nt} 1}+\mathrm{n}_{\mathrm{t}} / \tau_{\mathrm{nt} 2} \\
\mathrm{dp} / \mathrm{dt}=\mathrm{g}-\alpha_{2} \cdot \mathrm{p} \cdot\left(\mathrm{n}_{\mathrm{t} 1}+\mathrm{n}_{\mathrm{t} 2}\right)-\mathrm{p} / \tau_{\mathrm{p} 1}-\mathrm{p} / \tau_{\mathrm{p} 2}+\mathrm{p}_{\mathrm{t}} / \tau_{\mathrm{pt} 1}+\mathrm{p}_{\mathrm{t}} / \tau_{\mathrm{pt} 2} \\
\mathrm{dn}_{\mathrm{t} 1} / \mathrm{dt}=\mathrm{n} / \tau_{\mathrm{n} 1}-\mathrm{n}_{\mathrm{t} 1} / \tau_{\mathrm{nt} 1}-\alpha_{2} \cdot \mathrm{p} \cdot \mathrm{n}_{\mathrm{t} 1} \\
\mathrm{dn}_{\mathrm{t} 2} / \mathrm{dt}=\mathrm{n} / \tau_{\mathrm{n} 2}-\mathrm{n}_{\mathrm{t} 2} / \tau_{\mathrm{nt} 2}-\alpha_{2} \cdot \mathrm{p} \cdot \mathrm{n}_{\mathrm{t} 2} \\
\mathrm{dp}_{\mathrm{t} 1} / \mathrm{dt}=\mathrm{p} / \tau_{\mathrm{p} 1}-\mathrm{p}_{\mathrm{t} 1} / \tau_{\mathrm{pt} 1}-\alpha_{1} \cdot \mathrm{n} \cdot \mathrm{p}_{\mathrm{t} 1} \\
\mathrm{dp}_{\mathrm{t} 2} / \mathrm{dt}=\mathrm{p} / \tau_{\mathrm{p} 2}-\mathrm{p}_{\mathrm{t} 2} / \tau_{\mathrm{pt} 2}-\alpha_{2} \cdot \mathrm{n} \cdot \mathrm{p}_{\mathrm{t} 2}
\end{aligned}
$$

for which $g$ is the electron / hole pairs generation rate, $\alpha_{1}$ and $\alpha_{2}$ are the recombination rates, $n, n_{1}$ and $n t_{2}$ are densities of free and trapped electrons, $\mathrm{p}, \mathrm{pt}_{1} \mathrm{et}_{\mathrm{pt}}$ are densities of free and trapped holes, $\tau \mathrm{n}_{1}, \tau \mathrm{n}_{2}, \tau \mathrm{p}_{1}$ and $\tau \mathrm{p}_{2}$ are trapping time for free electrons and holes, $\tau \mathrm{n}_{\mathrm{t} 1}, \tau \mathrm{n}_{\mathrm{t} 2}, \tau \mathrm{p}_{\mathrm{t} 1}$ and $\tau \mathrm{p}_{\mathrm{t} 2}$ detrapping time for trapped electrons and holes. We can then assess densities of free electrons and holes that are used in (7) for surface potential assessment:

$$
\mathrm{dV} / \mathrm{dt}=\left[\mathrm{L} \cdot \mathrm{j} \cdot(1-\eta-\beta)-\mathrm{e} \cdot\left(\mu_{\mathrm{n}} \cdot \mathrm{n}+\mu_{\mathrm{p}} \cdot \mathrm{p}\right) . \mathrm{V}\right] / \varepsilon
$$

in which $\mathrm{L}$ is the sample thickness, $\mathrm{J}$ the incident flux of low energy implanted electrons $(20 \mathrm{keV}), \eta$ the secondary electron emission yield, $\beta$ is the surface leakage parameter, $\mathrm{V}$ the surface potential, e the elementary charge and $\varepsilon$ the material permittivity.

This model has been applied for Kapton ${ }^{\circledR}$ for which the different material input parameters required for the model have been extracted from previous experimental irradiation tests representative of space conditions (for instance those presented in Fig. 3). The numerical results are presented in the following section. The incident flux used in equation (7) has been extracted from the assessed electron spectra, taking, for each spectrum, the electron flux integrated for energies lower than $40 \mathrm{keV}$. The generation rate is directly linked to the high energy electron flux ( $g$ is proportional to this flux, the radiation dose per electron and the energy required to produce an electron-hole pair): knowing the g parameter extracted in given conditions (Kp>5 GEO like conditions - Fig. 3), it is possible to assess to some extent the $\mathrm{g}$ factor for the worst case conditions (taking electron flux integrated for energy higher than $200 \mathrm{keV})$. 
(151)

\section{NUMERICAL ANALYSIS OF CHARGING KINETICS IN WORST CASE IRRADIATION CONDITIONS}

\section{A. Worst case conditions with no radiation history}

In a first step, charging kinetics has been assessed in different worst case spectra (for irradiation duration equal to 5 min., 15 min. and 1 hour) on Kapton ${ }^{\circledR}$ with no radiation history. It does mean that delayed RIC is not present at the start of the irradiation. We can notice from Fig. 10 that Kapton ${ }^{\circledR}$ gets quickly charged up to very hazardous potentials even after 15 minutes irradiation. Charging kinetics are slightly different between the three cases because of, as mentioned in section II.A, the averaging process implied with the increasing irradiation duration (in the analysis of the worst case spectra) leading to a decrease of the low energy charging part.

These charging profiles are utterly different from those presented in Fig. 3 (in Kp $>5$ conditions). These differences can be explained by the fact that ratio between low and high energy fluxes is much higher in the defined conditions, leading to a higher charging flux and a much lower RIC than met in $\mathrm{Kp}>5$ conditions. Low RIC (and delayed RIC) is also noticeable during the relaxation process in which relaxation kinetics is very low, meaning that leakage current is insignificant.
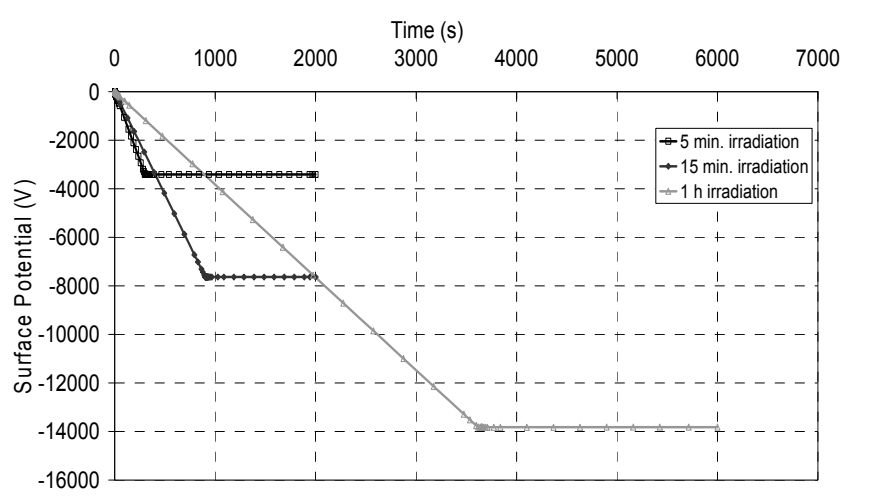

Fig. 10. Evolution of surface potential on a $127 \mu \mathrm{m}$ thick Kapton ${ }^{\circledR}$ piece in worst case irradiation conditions, without radiation history, and for irradiation duration equal $5 \mathrm{~min} .15 \mathrm{~min}$. and 1 hour

This situation is however quite severe since we did not take account radiation history and therefore the ionisation delayed effect that enhances significantly the effective electric conductivity and then the leakage current.

We have been able to demonstrate that worst case spectra are preceded by averaged irradiation conditions corresponding to the referenced IGE spectrum. The next step of the project was to study the charging kinetics under IGE like spectrum to analyse if this radiation condition can induce possible charging prior to the so-called worst case situations. The final step was to assess the charging potentials built-up on Kapton during worst case conditions taking into account radiation history. Both steps are described in the following section.

\section{B. Charging profile with the IGE spectrum}

Fig. 11 presents the evolution of charging potential on Kapton ${ }^{\circledR}$ irradiated with the IGE electron spectrum. We can notice on this figure that Kapton ${ }^{\circledR}$ presents fairly high potential during the first seconds of irradiation, contrary to what was observed in Fig. 3. This is due to the fact that the ratio between low and high energy fluxes is equal to 10 for the IGE spectrum versus 5 for the SIRENE spectrum. RIC is then lower and charging kinetics higher in IGE conditions. The surface potential however gradually fades away along the irradiation process: this can be explained in two points:

- It has been demonstrated in previous studies that RIC of Kapton ${ }^{\circledR}$ is not constant during irradiation but gradually rises up with the increasing radiation dose, leading to a gradual decrease of the surface potential

- The low energy charging flux is fairly low (100 pA. $\mathrm{cm}^{-2}$ ) and leakage current swiftly overcome the incident one leading to a quick initiation of the absolute surface potential decline.

Consequent RIC and low charging flux leads then to a surface potential close to zero after 500 seconds irradiation. We can then state that the IGE spectrum does not induce any significant charging over a long period of time but shall promote high levels of delayed RIC prior to the worst case conditions.

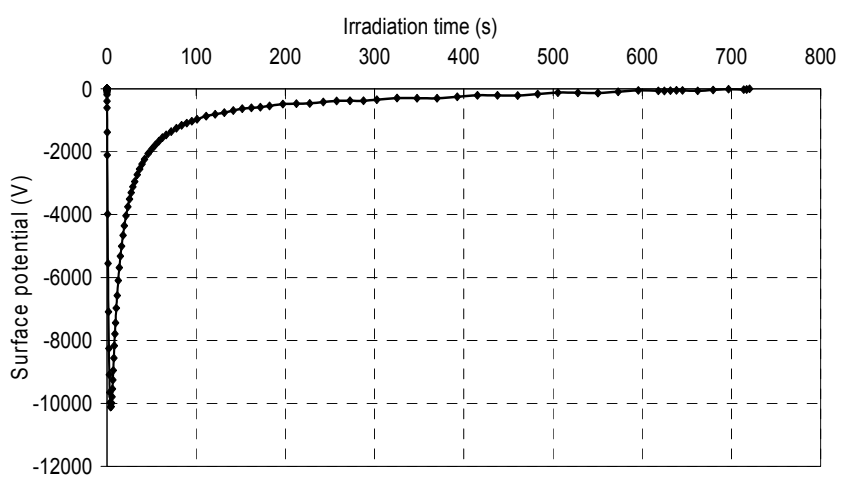

Fig. 11. Evolution of surface potential on a $127 \mu \mathrm{m}$ thick Kapton ${ }^{\circledR}$ piece with the referenced IGE electron spectrum

\section{Worst case conditions with radiation history}

The final step was to assess the charging potentials in worst case conditions preceded by the averaged IGE spectrum. Fig. 12 and 13 presents the surface potential built-up on Kapton ${ }^{\circledR}$ in $1 \mathrm{~h}$ worst case conditions preceded by 1 day (Fig. 12) or 1 month (Fig. 13) IGE radiation. In comparison with Fig. 10, we can clearly notice, for 1 month IGE radiation, that delayed RIC due to radiation history allows reducing significantly the charging risk in the defined worst case conditions. For only 1 day IGE spectrum, delayed RIC is here not high enough to avoid hazardous charging potential. One might therefore conclude that Kapton ${ }^{\circledR}$, due to its high sensitivity to ionization and the steep rise of its RIC with radiation dose, might not be subjected to any charging risks, except during its first moment 
(151)

in flight for which the injected radiation dose is not yet high enough to compensate the low energy charging current.

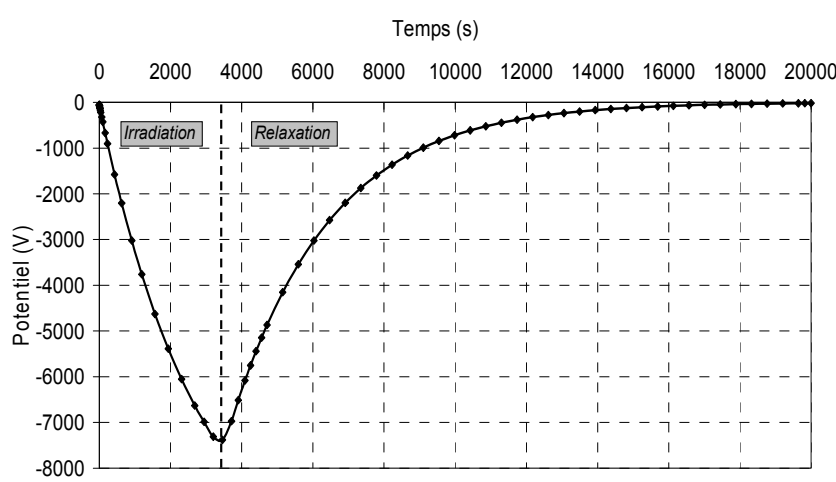

Fig. 12. Evolution of surface potential on a $127 \mu \mathrm{m}$ thick Kapton ${ }^{\circledR}$ piece in 1 hour worst case irradiation conditions, preceded by the IGE spectrum for 1 day (radiation history)

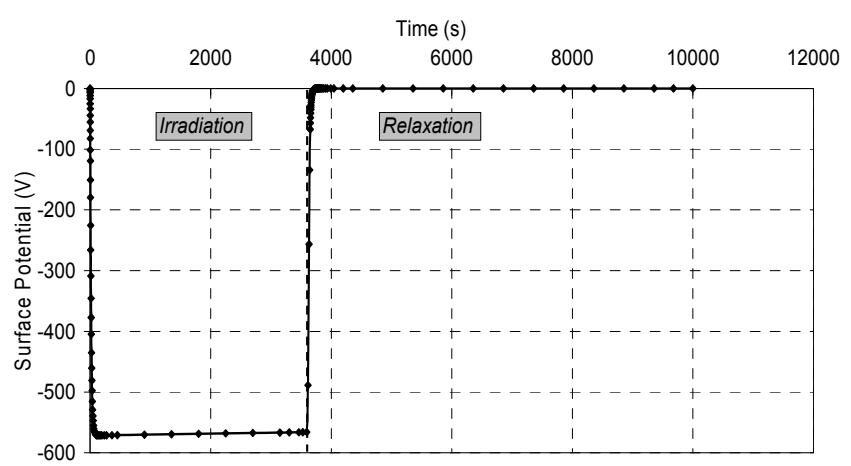

Fig. 13. Evolution of surface potential on a $127 \mu \mathrm{m}$ thick Kapton ${ }^{\circledR}$ piece in 1 hour worst case irradiation conditions, preceded by the IGE spectrum for 1 month (radiation history)

\section{CONCLUSION}

This current study allows the definition of worst case conditions (in term of charging issues) that seem to present higher charging risk in comparison with the $\mathrm{Kp}>5$ electron spectrum due to the higher ratio between low and high energy fluxes. As demonstrated in our numerical analysis on Kapton ${ }^{\circledR}$, this high ratio induces strong and hazardous charging levels due to the high level of low energy charging flux and the low radiation induced conductivity. However, charging effect is strongly smoothed by radiation history of the material. If we demonstrated that Kapton ${ }^{\circledR}$ should not be prone to any hazardous charging potential on flight, the situation shall nevertheless be very different for other space used dielectrics, such as fluorine based polymers, for which delayed RIC would certainly not be sufficient to overcome the high charging flux met in worst case conditions.

\section{ACKNOWLEDGMENT}

The authors would like to thank CNES, the French Space Agency, for fundings, technical and scientific support over the successive R\&T studies.

\section{REFERENCES}

[1] T. Paulmier, B. Dirassen, D. Payan, M. Van Eesbeek, "Material Charging in Space Environment: Experimental Test Simulation and Induced Conductive Mechanisms", IEEE Trans. Dielectrics and Electrical Insulation, Vol. 16, pp 682-688, 2009.

[2] R. Hanna, T. Paulmier, P. Molinie, M. Belhaj, B. Dirassen, D. Payan, N. Balcon, "Radiation induced conductivity in space dielectric materials", J. Appl. Phys., 115, 033713, 2014.

[3] Sicard-Piet, A., S. Bourdarie, D. Boscher, R. H. W. Friedel, M. Thomsen, T. Goka, H. Matsumoto, and H. Koshiishi (2008), A new international geostationary electron model: IGE-2006, from $1 \mathrm{keV}$ to 5.2 $\mathrm{MeV}$, Space Weather, 6, S07003, doi:10.1029/2007SW000368.

[4] A. Rose, "Recombination processes in insulators and semiconductors", Phys.Rev., vol. 97, pp. 322-333, 1955.

[5] J.F. Fowler, "X-ray induced conductivity in insulating materials", Proceedings of the Royal Society of London. Series A, Mathematical and Physical Sciences, vol. 236, pp. 464-480, 1956.

[6] B. Gross, R.M. Faria, and G.F. Ferreira, "Radiation induced conductivity in Teflon irradiated by x rays," J.Appl.Phys., vol. 52, pp. 571-578, 1981. 